\title{
NADHEZDA KRUPSKAIA: AÇÃO E LUTA DE UMA EDUCADORA COMUNISTA
}

\author{
NADHEZDA KRUPSKAIA: ACTION AND FIGHT OG A COMUNIST EDUCATOR
}

https://orcid.org/0000-0002-5863-3607 Dagmar de Mello e Silva ${ }^{\text {A }}$ https://orcid.org/0000-0003-1357-9202 Maria Onete Lopes Ferreira ${ }^{\mathrm{B}}$

(D) https://orcid.org/0000-0003-0989-3821 Maria Cláudia Reis C

\author{
${ }^{\text {A }}$ Universidade Federal Fluminense (UFF), Niterói, RJ, Brasi \\ ${ }^{B}$ Universidade Federal Fluminense (UFF), Angra dos Reis, RJ, Brasil \\ ${ }^{\mathrm{C}}$ Universidade Federal Fluminense (UFF), Niterói, RJ, Brasil
}

\section{Resumo}

Apresentamos a trajetória político-revolucionária de Nadhezda Konstantínovna Krupskaia e suas ideias forjadas na luta pela transformação social no contexto da Russa czarista. Destacamos sua coragem ao afirmar uma educação forjada na luta política de princípios socialistas e de igualde de gênero. Para tanto, baseamos o trabalho em obras de Samantha Lodi-Corrêa que se dedicou ao estudo biográfico desta educadora revolucionária que assumiu protagonismo na Revolução Russa, junto ao marido - Lenin -, apontando sua autonomia intelectual e militante, como mulher de vanguarda. Lamentamos a ausência de uma Krupskaia no Brasil, para destacar que nós, infelizmente, demoramos muito a compreender a natureza de classe da educação.

Palavras-chave: Krupskaia; educação revolucionária; feminista.

\begin{abstract}
We present Nadhezda Konstantínovna Krupskaia's political-revolutionary trajectory and her ideas forged in the struggle for social transformation in the context of Tsarist Russia. We highlight her courage in affirming an education forged in the political struggle of socialist principles and gender equality. For that, we base the work on works by Samantha LodiCorrêa who dedicated herself to the biographical study of this revolutionary educator who starred an important role in the Russian Revolution, together with her husband - Lenin -, pointing out her intellectual and militant autonomy, as a vanguard woman. We regret the absence of a Krupskaia in Brazil, to point out that we, unfortunately, took a long time to understand the class nature of education.
\end{abstract}

Keywords: Krupskaia; revolutionary education; feminist. 


\section{Nascimento de uma revolucionária}

A cidade de São Petersburgo - marcada pelo contraste de seus grandes palácios e construções deploráveis para os habitantes pobres -, nos anos de 1860, passava por uma lenta transição estrutural. O tzar Alexandre II deu início a medidas que pudessem tirar a Rússia de uma condição feudal rumo ao crescente capitalismo em franca ascensão no cenário mundial, particularmente na Europa. Portanto, não foi por sentidos éticos, de justiça social que medidas como a abolição da servidão camponesa, foram instauradas. Não é coincidência que o período em que os servos foram libertados, venha a ser o período de libertação dos escravos nos Estados Unidos, na Guerra de Secessão (1861- 1865), mas sim, por imperativos do capital que necessitava de trabalhadores "livres" e consumidores. Para Serge (1993) a abolição foi apenas um paliativo inteligente para dar soluções às condições sociais e econômicas que a Rússia enfrentava na época. Na verdade, ao acabar com a servidão feudal introduzia-se a servidão econômica. O lavrador "liberto" passava a trabalhar muito mais para sobreviver e essa medida proporcionou ao Império Russo o desenvolvimento do operariado (SERGE, 1993, p.16).

É nesse contexto político que nasce Krupskaia (1869), filha de pai militar e mãe educadora. De família pobre, desde cedo Krupskaia sofreu com a desigualdade social. Diante dessa realidade, começava a ser gestada sua afinidade com as ideias de cunho social, como a justiça e a luta contra a desigualdade de classe, valores éticos que herdara de seu pai - um humanista e simpatizante das causas em prol de mudanças sociais. Com a morte de seu genitor, ainda muito nova, Krupskaia deu início à sua vida de mulher trabalhadora e inaugura essa condição atuando na docência. Foi a forma encontrada para complementar a renda de sua mãe e, assim, sobreviverem.

Aos 14 anos, portanto, começou a dar aulas particulares à noite. Não levou muito tempo para que seu espírito revolucionário falasse mais alto e passasse a dar, também, aulas nãoremuneradas aos proletários numa escola dominical. A causa de sua dedicação à educação dos trabalhadores estava de acordo com o pensamento de um de seus pensadores preferidos, naquela fase juvenil: Tolstói. Este pensador propunha um sistema educacional transgressor para a época e, neste sentido, em total concordância com as aspirações revolucionárias de Krupskaia. Ou seja; um sistema sem hierarquias e sem autoridades, onde os alunos não se sentissem oprimidos por seus professores. Uma outra escola, concebida desde uma outra mentalidade precisava insurgir e subverter o estado ali instituído, posto que: 
[...] este estranho estado de psicologia, que eu chamaria de estado 'escolar' da alma, e que infelizmente todos nós conhecemos tão bem, consiste nisto em que todas as faculdades superiores - imaginação, gênio criador, dignidade - cedem lugar a outras faculdades semianimais: pronunciar sons sem atenção ao seu sentido, contar os números em fila, 1, 2, 3, 4, 5... suportar palavras, sem permitir à imaginação vivificála através das formas - em suma, abafar dentro de si todas as altas faculdades, para desenvolver apenas as faculdades compatíveis com o estado escolar - a apreensão, a tensão da memória e a atenção.(TOLSTÓI, apud INCONTRI, 1991, p.117 ) ${ }^{\mathrm{i}}$

Ideias como essas parecem ter sido uma das razões para que Krupskaia investisse seu tempo e conhecimento junto ao proletariado, a partir de trabalho voluntário, acreditando que somente os trabalhadores poderiam libertar outros trabalhadores, e um dos caminhos para tal libertação seria através da educação: “Quando comecei a compreender o papel que tinha que desempenhar o trabalhador na liberação de todos os trabalhadores, senti um desejo irresistível de estar entre os trabalhadores, de trabalhar com eles" (KRUPSKAIA In: BOBROVSKAIA, 1940, apud LODI-CORREA, 2016, p.158). É importante ressaltar que a mulher revolucionária, que nascia em Krupskaia, não desejava orientar, de fora, os trabalhadores. Seu desejo era ser um deles e, nesta condição, desde este coletivo, partirem de mãos dadas para o enfrentamento da opressão que afligia todos eles. A condição feminina de seu tempo histórico não era um empecilho em sua vontade de agir.

Como se observa também, Krupskaia, que crescera numa Rússia que destinava ao analfabetismo, a maior parte da sua população e, ao mesmo tempo, oferecia uma escola absolutamente comprometida com a preservação do ideal burguês, aos filhos das camadas aristocráticas, compreendera, muito cedo, a urgência em dirimir esse modelo escolar. Era preciso, no seu lugar, fazer brotar uma escola que proporcionasse o desenvolvimento integral, numa perspectiva omnilateral dos indivíduos e que, ademais, fizesse desabrochar a mentalidade solidária e o espirito de coletividade, que se contrapunham ao individualismo modelar da burguesia.

Ao longo dos tempos de ensinamentos oferecidos aos operários, Krupskaia foi aprofundando seus conhecimentos políticos e sociológicos, através de leituras da obra de Karl Marx. A professora russa aderiu às ideias do pensador alemão, que a seu ver, superava aquelas de seu mentor intelectual, até então - Tolstói. Com base nas leituras de Karl Marx, que via na existência das classes sociais em estado antagônico, o motor da história, conforme exposto em sua obra escrita em coautoria com Engels - "Manifesto do Partido Comunista ${ }^{\mathrm{ii}}$ ", o trabalho de Krupskaia iria ganhar um novo sentido. Suas aulas passaram a ser dadas pautadas em um método de ensino que não se restringisse somente em transmitir conhecimento, mas que 
desenvolvesse, junto aos alunos, a consciência de si como ser inserido numa classe social distinta, a classe trabalhadora. E por ser um ente na classe, consequentemente, faz parte de um sujeito coletivo. Tratava-se, pois, de um método voltado para uma política social revolucionária. Para isso ela abordava temas que, até então, eram destinados apenas às elites russas, procurando formar "novos homens", livres frente as diferenças de acesso à informação impostas pela alienação do sistema capitalista. Desta forma, a retenção e compreensão de determinados conhecimentos, antes reservados às escolas apenas frequentadas exclusivamente pelas elites, não se limitariam mais, apenas à aristocracia. É importante frisar essa valorização do conhecimento, sob a forma de conteúdo pela professora Krupskaia.

No trabalho com os operários, a proposta era oferecer um ensino que não se limitava ao ler e escrever, como era comum nas escolas voltadas aos trabalhadores. A palavra de ordem para esse ensino vinculava-se simplesmente na mínima instrução, no sentido de receber ordens por escrito e cumpri-las. A proposta de Krupskaia era avançar em conhecimentos elaborados que eram exclusivos da elite. Tudo isso aliado ao desenvolvimento da consciência política de seus alunos. (LODI-CORREA, 2016, p.161)

\section{$O$ reconhecimento politico}

Os ideais políticos revolucionários de Krupskaia se refletiam na formação de seus alunos, tanto que representantes do governo, ao visitarem as escolas em que ela atuava, perceberam a diferença no discurso e na forma de pensar de seus alunos, o que denotava a consciência de classe e a solidariedade que eles apresentavam entre si - dois fatores perigosíssimos para a estabilidade do então Império.

Devido a essa ameaça, a escola da revolucionária foi fechada pelos representantes do tzar, visto que haviam identificado, que os conteúdos ensinados em suas classes, não era "apropriado" para as camadas populares, pois apresentavam temas que somente a elite poderia ter acesso. Era notável a capacidade de discernimento dos operários e a consciência que tinham de sua exploração. Apesar do fechamento das escolas, as sementes subversivas tinham encontrado um solo fértil e não demoraria para se perceber que elas, na prática, já estavam germinando. Os trabalhadores haviam, sim, compreendido que juntos, eles compunham um movimento fortalecido e que assegurava a capacidade de enfrentar os poderosos.

Em 1895, a educadora deu continuidade à sua luta, visando a consolidação de seu trabalho de conscientização junto aos proletários, com suficiente força, ao ser capaz de envolvêlos nas movimentações populares decorrentes das ações políticas protagonizadas pela oposição ao tzar Nicolau II ${ }^{\mathrm{iii}}$. O envolvimento popular foi construído através da formação de grupos de estudos (sovietes) que debatiam sobre os ideais comunistas e a necessidade de criação do 
partido operário russo. Com o apoio de seu futuro marido, Lenin ${ }^{\text {iv }}$, em dois anos, a dupla conseguiu formar a "União de Luta pela Emancipação da Classe Operária", composta pelos distintos núcleos de operários da capital do Império Russo.

A participação de Krupskaia no movimento comunista foi bastante efetiva. Com a participação de Lenin - mesmo como preso político -, a revolucionária teve a iniciativa de fazer contato com outros trabalhadores através da distribuição de panfletos em frente às fábricas ${ }^{\mathrm{v}}$. Em pouco tempo, Krupskaia pôde experimentar os frutos de sua intervenção como educadora revolucionária. Não tardaria a assistir ao nascimento de uma classe trabalhadora consciente, que lutou pela redução da jornada de trabalho dos operários, de 16 horas consecutivas para 11 horas e 30 minutos por dia. A mulher educadora e feminista, Krupskaia teve um papel fundamental para a conquista desse direito.

A partir da sua experiência em contexto escolar, como professora, Krupskaia, junto às camadas trabalhadoras, inicia o projeto de educação libertária por ela idealizado, seguindo uma proposta coletivista, na qual não havia espaço para a reprodução da moral burguesa que subjugava a capacidade intelectual do proletariado e defendia a propriedade privada.

Para a educadora, não era possível pensar em uma educação livre enquanto a escola fosse lugar de reprodução do pensamento capitalista. Ela tinha a consciência de que a escola de seu contexto histórico e social, era essencialmente, um local destinado, de um lado a formar as lideranças políticas da burguesia e, do outro a formatar as mentes laborais para a aceitação daquela ideologia. Portanto, uma escola com aliada ao projeto de contenção de massas e controle social. Estava claro para Krupskaia que nessa perspectiva educacional burguesa, os interesses da classe dominante seriam repassados aos alunos de forma doutrinária. Isto é, sem nenhuma possibilidade de estes adquirirem a consciência de classe e, portanto, a consciência relativa às suas condições materiais de vida, enquanto classe explorada, ou mesmo sobre o valor de sua mão de obra. Nessa perspectiva educacional as camadas populares eram suprimidas do direito ao pensamento crítico e do acesso ao real conhecimento sobre suas condições de vida, pensava ela, conforme dirá Lodi-Corrêa (2018):

Krupskaia debateu o fato de que, na sociedade classista, a educação não é a mesma para o filho do operário, para o filho do pequeno-burguês e para o filho dos proprietários. A divisão de classes mantinha-se no ensino, de forma que, ao filho do operário cabe um ensinamento limitado, ao filho do pequeno-burguês um ensinamento para cargos administrativos e burocráticos, enquanto o filho da elite é preparado para desfrutar da vida e para governar. A escola para o trabalhador era limitada, com uma formação que permitia, basicamente, a leitura de instruções e para inculcar a moral burguesa fazendo dos trabalhadores rebanho manso e fácil de governar. (p.240). 
No modelo de educação burguês, cabe à elite definir quem pode ter acesso à informação e de que forma a tem. Esse controle do conhecimento compõe uma das principais formas de controle da moral burguesa - apenas aqueles detentores da intelectualidade e da justiça poderiam gerir o governo ou tomar as decisões que afetariam toda a população - restando à classe popular acatar e seguir as decisões de uma classe social que se mantém a partir da exploração do proletariado. Consciente dessa estrutura social, Krupskaia defendia uma "concepção materialista da história", que compreendia a história numa perspectiva de totalidade dialética, em que os "condicionantes" materiais numa dada realidade, são o peso mais relevante para uma proposição de análise ou tese. Nesta perspectiva, uma educação livre dos condicionantes de classe, se colocaria como possibilidade emancipadora dos oprimidos, assim como seria uma ferramenta provocativa das transformações dos indivíduos. Enquanto seres políticos, nesta compreensão revolucionária, os estudantes da classe trabalhadora, aprendem que é possível se rebelarem contra a opressão e lutar pela transformação da vida em sociedade. No entanto, uma tal proposta só se viabiliza se a classe trabalhadora assim se reconhecer e, se, desse modo, se dispuser a tomar para si a tarefa de educar seus filhos, pois enquanto a escola estiver sob o controle da burguesia, essa possibilidade será uma quimera. Um mero discurso vazio de significado, importante estratégia nos palanques de oportunistas da política.

A escola em qualquer sociedade capitalista, se deixada sob a orientação que satisfaz aos interesses burgueses, será sempre pensada sob a lógica interesseira do mercado, portanto o projeto político pedagógico, vindo do gabinete central, penderá sempre para o ângulo do utilitarismo forjado pelo mercado. E em tempos de crise do capital, o mais conveniente é o apelo autoritário camuflado no militarismo das escolas e na promessa do empreendedorismo ilusório.

\section{A falta de uma Krupskaia no Brasil}

A natureza de classe presente na educação, conforme se observa, estava muito clara no pensamento de Krupskaia, que muito cedo, percebeu a dualidade presente na finalidade escolar nas sociedades de classe, ao se municiar das leituras da obra de Marx e Engels.

Sob este ponto de vista, quando olhamos para o Brasil, que na opinião de alguns intelectuais orgânicos da classe trabalhadora, padece da ausência de uma experiência histórica revolucionária autêntica, Krupskaia se antecipa muito em relação à nossa experiência de educação revolucionaria. Ao comparamos seu pensamento com o olhar dos educadores brasileiros, a nossa história nos aponta que, apesar contarmos, inclusive com muitas mulheres 
nas lutas sociais travadas desde os primórdios do Império, nossos educadores só chamariam a atenção, para este fato, quase um século depois da experiência russa.

A pedagoga russa, no final do Século XIX, antes mesmo da Revolução de 1917, que em parte acontece em função de sua participação no processo de formação política do povo, já vaticinava que todo projeto de escola defendido pelas classes dominantes, não importava a sociedade, teria uma natureza dual. Era ponto pacifico para ela, que a formação escolar, ofertada para as camadas populares, não poderia ser a mesma oferecida à burguesia, sob pena da proliferação da miséria social em detrimento dos privilégios de alguns. E ainda, que a escola dos trabalhadores, fomentada pela burguesia, seria um meio de subjugação da classe. Nesse sentido, a dualidade da escola, não pode ser abertamente justificada, senão através de mentiras convenientes e oportunas.

Textualmente, nas palavras da autora de "A construção da pedagogia socialista":

No Estado burguês - seja uma monarquia ou uma república, não importa -, a escola é instrumento de subjugação intelectual de amplas massas nacionais. A finalidade da escola em tal Estado não é determinada pelos interesses dos estudantes, mas pelos interesses da classe dominante, isto é, pela burguesia, e os interesses de uns e de outros frequentemente são essencialmente bem diferentes. $\mathrm{O}$ objetivo da escola condiciona toda a organização do trabalho escolar, todo o modo de vida da escola todo o conteúdo de ensino escolar e da educação. Se procedermos de acordo com os interesses da burguesia, este objetivo vai ser diferente, variando na dependência de para qual segmento da população a educação se destina. Se a educação se destina às crianças da classe dominante, ela terá o objetivo preparar as pessoas capazes de deleitar-se com a vida e governar. (KRUPSKAYA, 2017, p. 65)

Essa condição nós só iriamos perceber com Paulo Freire, quando a Revolução Bolchevique já corria o mundo como espectro que rondava o capitalismo central, ainda que na periferia do sistema, em solo brasileiro, a tormenta fosse a fome e a miséria que havia produzido Canudo e Lampião. Foi, este o cenário que fez nascer Freire, o brasileiro que inauguraria um pensamento revolucionário sobre a educação e que forjou uma prática educativa junto aos analfabetos camponeses, mesmo sem ancorar diretamente seu método ao pensamento de Marx. Método, de algum modo, semelhante ao de Krupskaia, visto que sua pedagogia nasce da crítica que ele desenvolve sobre a miséria que predominava no sertão nordestino. Pedagogia que iria marcar o resto de sua vida, sempre empenhada na mesma luta.

Como se sabe, a vida de Paulo Reglus Neves Freire (1921-1997) se confunde com a luta por uma educação libertadora. Essa luta, iniciada num Brasil ainda típico da Idade Média, pois assim eram as condições de existência predominantes no interior do Nordeste brasileiro. Por lá, o sertanejo se deparava com uma realidade de conotações pré-capitalistas por quase todo o século XX. Paulo Freire, portanto, na juventude habitou o mesmo cenário onde prosperou o movimento conhecido na história como Cangaço, imortalizador da lenda Lampião, que levou ao episódio chamado de 
Canudos, sob a liderança de Antônio Conselheiro e para sempre vivo em "Os Sertões”, narrado na prosa de Euclides da Cunha (FERREIRA; MARTON, 2000, p. 226).

Mesmo sob tempos e realidades distintas Krpskaia já havia compreendido que a educação era a via de transformação do sujeito e, por consequência de transformação de toda sociedade, realizada por sujeitos conscientizados acerca de como a sociedade se organiza. Graças à sua formação autodidata, apressou-se como professora, a se desviar intencionalmente da rota reprodutora da escola burguesa e, conforme já frisado, passou a pautar sua pratica docente com a firme finalidade de politizar seus alunos, para que, conscientes de seu lugar social, se encorajassem a lutar pelo fim da opressão.

Quando olhamos para o Brasil, à luz de Krupskaia, fica bem nítida a ausência desta visão precoce na ex-colônia portuguesa. Aliás, o que se pode concluir é que o processo de colonização nas nossas terras foi tão eficaz que, inclusive, cem anos após a Independência, ainda não havíamos despertado para uma compreensão crítica, sobre a política para a educação escolar, nas terras tupinambás. Nem mesmo os signatários do Manifesto de 1932 atentaram para o fato de que a escola, ainda muito incipiente, que era oferecida por aqui, servia apenas como trampolim social para as camadas médias. E desse modo, o Manifesto clamava por uma educação, até certo ponto, universalizada, todavia o projeto era assentado no ideário burguês e fazia a defesa da novidade educacional, que ficou conhecido como Escola Nova, como redenção da sociedade.

Pascoal Leme, que era um dos signatários do Manifesto (e é apontado como um comunista dentre eles) não puхои a brasa para a sardinha dos trabalhadores. Para ele, a rigor, a educação capaz de elevar a consciência da classe trabalhadora brasileira, dependia de uma melhor distribuição da renda social e de um maior ganho cultural. Ou seja, sem esta condição prévia, a escolarização não cumpriria um papel mais relevante na luta dos trabalhadores, no olhar de Leme.

Parece que naquele Brasil, que chegou aos anos de 1930, e que se assemelhava muito à Rússia de Krupskaia, a escola não tinha sido compreendida como reforço do projeto hegemônico da burguesia nacional, sequer, por Leme. Tampouco, para ele, naquele momento, a escola foi percebida como possibilidade de ganho político para os trabalhadores. Não lhe ocorria, talvez, que a escola era reflexo das contradições sociais, ou seja, da divisão de classes, conforme percebeu a professora russa. Diferentemente da compreensão de Krupskaia, a luta de classe, na sociedade brasileira, ao que nos parece, não encontrava, no olhar sob a escola, um reforço para nenhum dos lados, aos olhos pioneiros. 
E como sabemos, antes dos chamados Pioneiros da Educação, não havia tido no Brasil, nenhum movimento que relacionasse a escola aos trilhos do "progresso". Nem mesmo o empoderamento da ideia de progresso como lema/letreiro na bandeira republicana foi capaz de impulsionar a defesa da educação, pela intelectualidade da época. Ao contrário do anjo da história apresentado por Benjamin (1994), na história da educação brasileira, fomos arrastados pela tempestade do progresso rumo as promessas de um paraíso futuro, esquecendo-nos de olhar para trás e voltamos as costas para o amontoado de ruínas de nosso passado.

Há um quadro de Klee que se chama Angelus Novus. Nele está desenhado um anjo que parece estar na iminência de se afastar de algo que ele encara fixamente. Seus olhos estão escancarados, seu queixo caído e suas asas abertas. O anjo da história deve ter esse aspecto. Seu semblante está voltado para o passado. Onde nós vemos uma cadeia de acontecimentos, ele vê uma catástrofe única, que acumula incansavelmente ruína sobre ruína e as arremessa sobre seus pés. Ele gostaria de deter-se para acordar os mortos e juntar os fragmentos. Mas uma tempestade sopra do paraíso e prende-se em suas asas com tanta força que o anjo não pode mais fechá-las. Essa tempestade o impele irresistivelmente para o futuro, ao qual ele volta as costas, enquanto o amontoado de ruínas diante dele cresce até o céu. É essa tempestade que chamamos de progresso (BENJAMIN, 1994, p. 226).

Não fosse pela curta passagem de Paulo Freire, como educador popular no início dos anos de 1960, o Brasil somente iria ver a educação projetada como ferramenta capaz de instrumentalizar a luta da classe trabalhadora, no final do século passado, com os movimentos pela redemocratização.

\section{Krupskaia e o feminismo}

Krupskaia também nos deixou contribuições para uma coeducação de base feminista. A coeducação entre sexos, para ela, deslegitimaria a concepção de que existem tarefas designadas aos meninos e às meninas ("coisas de meninos e coisas de meninas"), da mesma forma que não se deve apropriar a educação e o ensino de acordo com o sexo. Aprender é um ato transgressor e necessário a todos os indivíduos. E a emancipação é alcançada através da possibilidade de ambos os sexos deterem o conhecimento e agirem a partir dele, de posse de ideias claras e evidentes sobre a realidade na qual habitam. Ensinar aos meninos a realizarem tarefas, historicamente consideradas femininas, como cozinhar e praticar os afazeres domésticos, seria uma forma de adquirir autonomia e potência frente as tarefas da vida. E era também um modo de questionar a naturalização dos papéis, conforme cristalizados pelo modelo patriarcal presente no tal processo civilizatório desde a origem da propriedade privada dos meios de produção.

No tempo de Krupskaia, essa realidade era comum apenas nas famílias de trabalhadores, 
em que as tarefas eram compartilhadas entre ambos os sexos, visto que numa casa de família burguesa, as mulheres ficavam restritas aos espaços privados, apenas os homens tinham direito ao espaço público. Porém, nas famílias desprivilegiadas, a mulher também participava das atividades operárias. A educação livre seguiria nessa vertente, a fim de se quebrar com o ciclo da divisão sexual do trabalho. Além disso, faria parte de uma estratégia de empoderamento das mulheres e ruptura de uma posição socialmente depreciativa. Sobre o pensamento de Krupskaia a respeito da coeducação, Lodi-Corrêa (2018) comenta:

[...] a educação é defendida como elemento necessário a todos, independente de sexo e, principalmente, independente de classe social porque, para além da discussão de sexo, o elemento mais discriminador se dava por parte das questões de classe. Uma menina de classe alta tinha acesso à educação, mesmo que limitada, enquanto o menino das classes desprivilegiadas também estava fora das escolas. Nesse sentido, e alicerçada em uma proposta comunista, ela reforçou a necessidade de uma educação como elemento de transformação social. (p. 241).

$\mathrm{Na}$ visão da pedagoga, era necessário garantir as mesmas oportunidades de acesso e condições básicas de educação para meninos e meninas, a fim de que se proporcionasse um ambiente com material didático, vestimenta adequada, boa alimentação e exercícios que estimulassem o desenvolvimento motor e cognitivo dos alunos. Somente a partir desses recursos é que o projeto de uma educação coletivista, solidária e humana poderia seguir adiante e interditar, desse modo, os princípios moralizantes de um ensino de cunho capitalista. Era esta a sua proposta para impedir a sustentação dos fundamentos competitivos e classistas do princípio educativo burguês. Ou seja, antes mesmo da Revolução já seria possível uma educação capaz de minimizar a eficácia de subjugação da educação burguesa, que, desse modo não se realizaria completamente.

A propósito da distinção dos papéis feminino na história em relação ao lugar das mulheres trabalhadoras e burguesas, é curioso observar, que há uma ocultação das mulheres trabalhadoras, fazendo crer que ao falar da mulher burguesa, contempla-se todas as mulheres. Quando se examina a realidade fora da narrativa dos vencedores, como diria Walter Benjamin (1994), a primeira coisa que nos chama a atenção, é que as mulheres pobres sempre exerceram aquelas funções não permitidas às mulheres da elite. Na narrativa histórica positivista, há uma total invisibilidade das mulheres pobres, embora na vida real as coisas se passassem de modo muito distinto.

Essa ocultação, comumente escapada aos nossos olhos, uma vez que foi de tal modo naturalizada pelo preconceito machista patriarcal, que mesmo sem nos darmos conta, muitas vezes endossamos estas narrativas. Daí que, com frequência tendemos, a justificar a crítica à 
não divisão sexual do trabalho apelando para a necessidade de autonomia dos homens em situações de necessidade. Já em relação às mulheres desenvolverem tarefas ditas masculinas, não encontramos a mesma justificativas. As mulheres podem fazer as mesmas coisas que os homens fazem, simplesmente porque são tão capazes, quanto. Como se as coisas atribuídas aos homens pelo patriarcado machista, fossem necessariamente superiores àquelas destinadas às mulheres.

Ora, todas as tarefas de fazimento de coisas, não importa qual, são frutos de aprendizagens. Aprender a fazer, traz do espirito e do intelecto um fundamento necessário e não classificável e só acontece ao se pôr em ação, conjuntamente, mão e cérebro. Toda classificação é autoritária e como o autoritarismo está assentado na divisão do trabalho, nascido com o advento da propriedade privada, classificar é um traço capitalista.

Entretanto é muito interessante observar que Krupskaia atinava com este pensamento, ainda que intuitivamente e, que não tenha se debruçado numa escrita propriamente sobre esses temas que chamamos hoje de feministas. E, verdade seja dita, não cabe, apontar seu pensamento como atrasado no tocante ao feminismo, uma vez que as condições materiais da história não eram, em absoluto, favoráveis ao desvelamento de tais fundamentos.

A proposta de educação de Krupskaia, todavia trazia este fundamento de não aceitação da hierarquia de tarefas. Estava claro para ela que a distinção de tarefas entre meninos e meninas era algo a ser superado para o bem da humanidade. Ela compreendia que o único fundamento a ser empreendido na prática educativa advinha da necessidade de formar pessoas solidárias, com espirito coletivo e capazes de empreender a luta revolucionária para a emancipação da humanidade, portanto um fundamento amoroso. E o amor não classifica, acolhe.

A revolucionaria russa aprendera com Marx que a escolarização deveria estar apartada do princípio do trabalho, uma vez que não é possível a construção de um mundo humano sem o trabalho. Todavia um trabalho não entendido desde seu estado abstrato, esta mutação capitalista com que se compreende a atividade humana na sociedade burguesa. Princípio educativo que seria formulado um pouco mais adiante por Gramsci, desde o cárcere. Ao ter esta clareza sobre o lugar do trabalho na formação humana, Krupskaia, sabia que a divisão de tarefas por sexo não poderia ser admitida, pois ela é parte da visão alienada sobre os fundamentos da vida em sociedade. E por isso mesmo, defendia que na escola as crianças aprendessem a fazer, juntas, todas as coisas.

Evidentemente ela não propôs receitas, pois sabia que ali estavam todas as pessoas, inclusive educadores e educadoras, aprendendo a fazer a escola revolucionária. Escola que, 
portanto, ainda estava por ser construída. Era um invento e um experimento que iria se realizando juntamente com a revolução.

A trajetória revolucionária de Krupskaia teve papel central na configuração de um novo modelo de educação entre os séculos XIX e XX, e suas contribuições para o processo de formação de um "novo sujeito" foram fundamentais para a releitura da educação na sociedade. A revolucionária russa pôde, através de seus escritos e práticas pedagógicas, contribuir para o debate a respeito da construção de uma consciência política que era negada às classes economicamente desprivilegiadas. Consciência esta que, em pensamento, estava ocultada na educação burguesa e precisava ser afirmada numa escola socialista.

Sem dúvidas, o pensamento marxista-leninista, somado à sua experiência precoce no magistério, foram fatores decisivos para a formulação de uma proposta educacional emancipadora, que tivesse como base a justiça social. A conscientização dos sujeitos quanto aos seus direitos e deveres tornava-se uma ferramenta indispensável para o alcance de um mundo mais justo e de oportunidades iguais, não apenas entre os gêneros sexuais, mas, também, entre as classes, até que essas distinções não definissem mais os rumos da sociedade.

Trazer o passado à memória, através da vida revolucionária dessa mulher, além de nos permitir refletir sobre a função social da Educação a partir de suas ideias é também, uma forma de escovar a história à contrapelo e apontar o lugar da mulher nas transformações sociais, papel esse que poucas vezes assumiu protagonismo, quando muito, relegado a uma condição coadjuvante. Condição esta que Krupskaia se negou a aceitar.

\section{Considerações finais}

Nestes tempos de recrudescimento das ideias de extrema-direita, especialmente no Brasil, é muito oportuna a ampliação do debate acerca das ideias revolucionárias, através das quais a humanidade deixa exemplos de práticas educativas e políticas que fizeram um diferencial histórico e social. Estudar e falar de Krupskaia neste momento tóxico em que atravessamos uma tragédia, aprofundada por um governo de natureza neofascista, cumpre algumas tarefas necessárias. Uma destas tarefas é o fortalecimento da energia intelectual que, mais forte, nutre o espírito e amplia a imunidade da alma, necessária para a elevação da esperança revolucionaria.

Essa viagem, ainda que curta, no pensamento de Krupskaia, para nós educadoras/professoras, essencialmente nos aviva a certeza de que a educação como ela propunha, tem poder transformador. Neste sentido, mesmo em tempos de aulas através de 
sistemas e plataformas remotas, podemos extrair da lucidez e das ideias desta mulher, que muito antes de falarmos em feminismo, fez de sua luta uma revolução, no tocante ao papel das mulheres na sociedade, força aprendizagens para as nossas aulas e nossa luta.

Certamente estamos, apesar do desânimo que insiste em nos abater, em busca de revigorar a nossa força para afirmarmos com Krupskaia, que, sim a escola também é para nós um locus para desenvolvermos a consciência e o saber que as camadas trabalhadoras necessitam para fortalecer a resistência e a preparação da luta a ser empreendida na derrubada de ideologias neoliberais e capitalistas que colocam o capital acima da vida humana.

\section{Referências}

BENJAMIN, Walter. Magia e Técnica, arte e política: ensaios sobre literatura e história da cultura. São Paulo, Ed. Brasiliense, 1994.

FERREIRA, M. Onete Lopes; MARTON, Silmara L. Paulo Freire: uma existência de amor e de luta contra a opressão, p 222 a 231. Revista Universidade e Sociedade. Brasília. Ano XXX - No 66 - julho de 2020

INCONTRI, Dora. Tolstoi e a anti-pedagogia: uma proposta de educação libertária. Revista da Faculdade de Educação, v. 17 nº 1-2, 1991. Disponível em:

https://www.revistas.usp.br/rfe/article/view/33465

KRUPSKAYA, N.K. A construção da pedagogia socialista. São Paulo: Expressão popular, 2017

LODI-COREA, Samantha. Nadezhda Krupskaia: uma estrela vermelha. Uberlândia, MG: Navegando publicações, 2018.

Nadezhda Krupskaia: por uma educação revolucionária. Germinal: Marxismo e Educação em Debate, Salvador, v. 10, n. 3, p. 236-244, dez. 2018.

Entre a Pena e a Baioneta: Louise Michel e Nadehzda Krupskaia, educadoras em contextos revolucionários. Tese de doutorado apresentada ao Programa de Pós-Graduação em Educação de Faculdade de Educação da Universidade Estadual de Campinas. Orientadora: Prof ${ }^{a}$ Dr $^{a}$. Mara Regina Martins Jacomeli, Campinas, 2016. Disponível em: http://repositorio.unicamp.br/handle/REPOSIP/321601

SERGE, Victor. O ano I da Revolução russa. São Paulo: Ensaio, 1993 
${ }^{\text {i } T o l s t o i, ~ L e ́ o n . ~ L a ~ L i b e r t e ́ ~ d a n s ~ L ’ E ́ c o l e . ~ P a r i s: ~ N o u v e l l e ~ L i b r a i r i e ~ P a r i s i e n n e, ~} 1888$.

ii MARX, Karl \& ENGELS, F. Manifesto do Partido Comunista. Coletivo das Edições Avante, Lisboa, 1997

iii Tolstoi, Léon. La Liberté dans L’École. Paris: Nouvelle Librairie Parisienne, 1888.

${ }^{\text {iv }}$ Krupskaia havia conhecido Lenin nos idos de 1893 e em 184/1895, suas relações se estreitaram no plano afetivo, pois nutriam uma simpatia profunda um pelo outro, dada a admiração com que viam, de forma reciproca o comprometimento com as lutas, desde o mesmo ideal de libertação dos operários da opressão. Em 1896 ela é presa e em 1897/1898 seria deportada para a Sibéria, a pretexto de encontrar o noivo, Lenin. Casam-se, finalmente e permanecerão juntos até a morte de Lenin.

${ }^{v}$ Não muito depois da vitória pela redução da jornada de trabalho, Krupskaia foi presa por panfletagem ilegal e divulgação de ideias comunistas. Permaneceu por sete meses na prisão "Pedro e Paulo" e logo após seu julgamento e condenação, teve de ser exilada. (Lodi-Corrêa, 2018). 